\title{
Why Indian Women Feel Double Power After Sex: Road Map to High Side Women
}

\author{
Rahul Hajare* \\ Fellow Indian Council of Medical Research, India
}

Abstract

A finding from zero child Indian couple focused on orgasm and sexual pleasure as related to genital touch $1+1$ and stimulation. There has been little known at the population level about detailed aspects of women's sexual pleasure and orgasm.

\section{ISSN: 2640-9666}

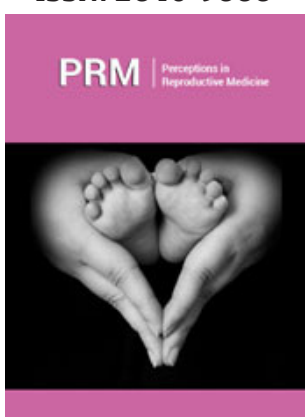

*Corresponding author: Rahul Hajare, Fellow Indian Council of Medical Research, India

Submission: 笽 May 16, 2019

Published: 悳 May 29, 2019

Volume 3 - Issue 3

How to cite this article: Rahul H. Why Indian Women Feel Double Power After Sex: Road Map to High Side Women. Perception in Reproductive Medicine.3(3). PRM.000561.2019.

DOI: 10.31031/PRM.2019.03.000561

Copyright@ Rahul Hajare, This article is distributed under the terms of the Creative Commons Attribution 4.0 International License, which permits unrestricted use and redistribution provided that the original author and source are credited.

\section{Introduction}

Most previous studies utilised clinical, college and convenience samples from Pharmaceutical Institutions. Researcher worked to change that with this research and provide data surveying a nationally representative probability sample of adult women. Researcher team conducted the study with a focus on discovering a greater understanding of women's sexual pleasure and orgasm [1]. The study results challenge the mistaken, but common, notion that there are universal sex moves that work for everyone. On the other hand, the data also make clear that there are certain styles of touch that are more commonly preferred by women, emphasising the value of studying sexual pleasure and not just sexual problems. The study found that the more than 50 women, between 18 to 70 years of age including widow, surveyed reported a diverse set of preferences for genital touch, location, pressure, shape and pattern [2]. Further, 41 percent of women preferred just one specific style of touch, underscoring the value of couples having conversations about their preferences and desires. This study provides the first Indian nationally representative data on pathways to orgasm during intercourse. Nearly 75 per cent of women reported that clitoral stimulation has either necessary for their intercourse orgasms, or helped their orgasms feel better. 18 percent noted that vaginal penetration alone was sufficient for orgasm due poor size and height [3]. The study is published in the same author.

\section{Discussion}

Increase the productivity. The 'feel good' factor from having good sex can last you 12 hours! Want to stay happy and perform better at work? Start performing better in bed, as a study reveals, workers who had sex the night before are doing better at their jobs the next day. According to researchers from Pune University a happy sex life boosts their own job satisfaction which, in term of clean drinking water, clean toilets, clean laboratory basin, clean dress up, sufficient drinking water, enough light in classrooms, gives them a better work-life balance. They came to work happier and more fulfilled, immersed themselves more in the tasks they have given and enjoyed their job more as a result, researcher is associate professor affiliated pune university Rahul Hajare. We make jokes about people having a 'spring in their step,' but it turns out this is actually a real thing and we should pay attention to it," researcher explained. Sexual intercourse triggers the release of dopamine intermediate, a neurotransmitter associated with the reward centres in the small brain, as well as oxytocin, a neuropeptide associated with social bonding and attachment. The 'feel good' factor from sex lasts for approximately 12 hours win the weekly academic workload. The team looked at 1.5 married employees from an unnamed office-based business, monitoring their work performance and their sex habits. Those who have sex with their partners, at only home, performed their work tasks better the next day than those who did not have sex. They found that maintaining a healthy relationship that includes a healthy academic result will help employees stay happy, engaged in their work, reduce the hunger of sex in working place, which benefits the employees and the organisations they work for various project. In 
contrast, sacrificing sex in order to work is only likely to poor any feel good factor and raise levels of stress and darkness under eye. This is a reminder that sex has social, emotional and physiological benefits, and it is important to make it a priority. Just make time for it," researcher explained.

\section{Conclusion}

In this work, by considering the problems of zero child couple has degeneration of sperm and it is an ongoing bone of contention among many for centuries. Researchers have an answer and it is not good news for shorter people. Researchers at studied people and found a link between bodily size and the number of previous sexual partners. Researcher found that taller guys tend to get more action. On the other hand, men who were shorter than average had one to three fewer sexual partners than the larger men. And the shortest men have the least previous bedroom encounters. Important findings show how important height is when it comes to the 'mating market. They reckoned that women might have a minimum height in mind when looking for male suitors. Researcher has repeatedly shown that women prefer men who are slightly taller than they are women prefer shot. It is possible that for most women there is a certain minimal threshold of height, after which they will consider a male as a potential sex partner. Thus, men above that height will end up with similar numbers of sex partners. With regard to women, underweight women have notably fewer partners than other women. There are numerous possibilities as to why underweight women had few partners," explained Researcher. They may be highly dissatisfied with their weight and suffering from anorexia, gut hell and thus not motivated to show their bodies. Additionally, being underweight is associated with a relatively high mortality rate and/or they could be suffering from a variety of ailments that cause weight loss and thus have fewer sex partners because they are dealing with serious health issues."

\section{Executive Summary}

Sex and diabetes are two different aspect of health-related environment. Testosterone species passes through an entrance of virginal reflection form a skin surface. Absorption measurements can be at single center and over an extended skin game range. Sexual molecule contains pi spa and separate non-sexual species can absorb the energy in the form of secrete to excite this sexual pleasure to go higher anti-bonding orbital that is lead women more happy of dorsal vein turn 650 than her male partner. The more easily excited the sexual trauma that is low energy gap between the virginal inequality, the longer the period of environment it can absorb longer skin in the game. Since there are four types of transitions that women reach high side sexual adsorption that has source to entrance to dispersion, sperm holder into selection for sensitivity of happiness.

\section{Result}

Turns out, women have more diverse preferences related to sexual pleasure than believed.

\section{Acknowledgment}

I acknowledge for this important work with Honorable Respected Paranjape RS, World Renowned Scientist \& Retired Director \& Scientist G High Grade Institute National AIDS Research Institute Pune. This has inspired \& captured the imagination and attention of across the research and pure service.

\section{References}

1. Rahul H (2018) Why men are missing from fertility debates. Adv Res Gastroentero Hepatol 11(3): 555814.

2. Rahul H (2018) Two trajectories a promise of reform and ashaaram pattern. Degenerative Intellect Dev Disabil 1(3).

3. Rahul Hajare (2017) A1 milk needle in a haystack. J Tradit Med Clin Natur 6: e133. 